\title{
O COMPORTAMENTO ALIMENTAR E A INSATISFAÇÃO COMA IMAGEM CORPORAL DAS ATLETAS DO BASQUETE FEMININO DE UMA CIDADE DO INTERIOR DE SÃO PAULO
}

\author{
GAZOLLA, Micheli Bordonal; UEHARA, Priscila Fuzaro. Nutricionistas graduadas pela \\ Universidade de Franca. \\ MANOCHIO, Marina Garcia. Docente do curso de Nutrição da Universidade de Franca. \\ E-mail: mamanochio@yahoo.com.br. \\ PONTIERI, Márcia Helena. Docente da Universidade Federal do Triângulo Mineiro - ICTE.
}

\begin{abstract}
RESUMO
Os principais Transtornos Alimentares - TAs são a anorexia e a bulimia nervosas. Verificou-se o comportamento de atletas com relação à alimentação, controle de peso e a avaliação da imagem corporal. Observou-se que: $25 \%$ apresentam distorção leve da imagem corporal e 16,66\%, distorção moderada. Nas Silhuetas de Stunkard et al., 66,66\% superestimam o peso, 16,67\%, possuem insatisfação com relação à magreza. A maioria das atletas apresentam composição corporal adequada, mas revelam distorção da sua imagem corporal.
\end{abstract}

PalavRas-chave: Transtornos alimentares; Jogadoras de basquete; Imagem corporal.

\begin{abstract}
The most important eating disorders are anorexia and bulimia nervosa. This study intended to appraise athletes' behavior related to food, weight control and body image. The obtained results were: $25 \%$ present light distortions of their body image and 16,66\% show moderate distortions. Based on the silhouettes of Stunkard et $a l ., 66,66 \%$ overestimate their weight, $16,66 \%$ show dissatisfaction in relation to their thinness, $16,67 \%$ are pleased with their body weight. The majority of the athletes presents proper body composition, but presents a distortion of their body image.
\end{abstract}

KEYwORDs: Eating disorders; Basketball players; Body image. 


\section{INTRODUÇão}

Os quadros psicopatológicos caracterizados por intensas alterações no comportamento alimentar são denominados Transtornos Alimentares - TA (SHILS et al., 2003; BIGHETTI et al., 2006). Os principais são anorexia nervosa (AN) e bulimia nervosa (BN). Esses distúrbios são desencadeados por fatores biológicos, psicológicos, sociais e culturais podendo assim prejudicar o desenvolvimento biopsicossocial do indivíduo (BIGHETTI et al., 2006; BORGES et al., 2006). Segundo Pinheiro et al. (2006), estudos indicam que fatores genéticos propiciam a suscetibilidade do indivíduo a desenvolver esses tipos de TA.

Os portadores de TAs são, em sua maioria, adolescentes do sexo feminino, raça branca e alto nível socioeconômico e cultural, embora atualmente podese observar que esse grupo está mais heterogêneo, sendo possível diagnosticar esses transtornos em adolescentes do sexo masculino, raça negra, préadolescentes e com baixo nível socioeconômico (BORGES et al., 2006).

A BN é caracterizada por episódios repetidos de grande ingestão alimentar (episódios bulímicos, do inglês binge eating) e uma preocupação excessiva com o controle do peso corporal (BORGES et al., 2006). Muitas vezes, esses pacientes utilizam métodos compensatórios inadequados para o controle de peso, tais como: indução de vômitos, uso de laxantes e diuréticos, inibidores de apetite e hormônios tireoidianos (BIGHETTI et al., 2006). Este TA é subdividido em tipo purgativo e não-purgativo. No subtipo purgativo ocorre a autoindução de vômitos ou uso indiscriminado de laxantes, diuréticos e enemas. O subtipo nãopurgativo é caracterizado por outros tipos de comportamentos compensatórios, tais como: jejum ou exercícios físicos excessivos, não sendo observado uso de laxantes, diuréticos e vômitos (BORGES et al., 2006; CORDÁS et al., BIGHETTI et al., 2007).

Já a AN é caracterizada pela perda de peso acentuada e intencional, baseada em uma dieta extremamente restrita, devido a uma distorção da imagem corporal buscando a magreza. Neste tipo de TAé observada também a ausência do ciclo menstrual regular (BORGES et al., 2006; CORDÁS et al., 2007). A ausência do ciclo menstrual, denominada amenorreia, é caracterizada por baixos níveis de estrógeno circulante. Pode ser causada pelo baixo consumo calórico, intenso treinamento, retardo no início da função menstrual, estresse, baixo peso corpóreo e baixa porcentagem de gordura corporal (WOLINSKY; HICKSON, 1996). Nos homens é observada a diminuição da libido e potência sexual (NUNES, 2006). Segundo Cordás (2007), a anorexia é subdivida em tipo restritivo e purgativo. No primeiro subtipo os portadores da patologia iniciam restrições alimentares e, no tipo purgativo, ocorrem episódios de compulsão alimentar seguidos de métodos compensatórios (indução de vômitos, uso de laxantes e diuréticos). Para a American Psichiatric Association, as alterações psicológicas dos pacientes bulímicos não são muito diferentes em comparação aos pacientes anoréxicos, pois ambos apresentam sentimentos depressivos e pensamentos autodepreciativos após os episódios de compulsão alimentar (CRISP; PALMER; KALUCY, 1976).

Apesar de não apresentarem níveis de prevalência elevados, esses transtornos vêm sendo citados como grandes e importantes problemas de saúde pública nos últimos anos. Amédia anual de incidência de anorexia é de aproximadamente 18,5 por 100 mil mulheres e de 2,25 por 100 mil homens. Na bulimia nervosa, a incidência é de 28,8 por 100 mil mulheres e de 0,8 por 100 mil homens (CORDÁS et al., 2007). Além do perfil dos portadores citado acima, o ambiente esportivo pode ser um meio ampliador de pressões socioculturais que são motivadas pelo ideal de um corpo magro e perfeito, levando a alterações da imagem corporal e comportamentos sugestivos de transtornos alimentares (OLIVEIRA et al., 2003). Sendo assim, a insatisfação corporal leva a comportamentos impróprios para manutenção do baixo peso corporal (NEUMARK-SZTAINER et al., 2006).

Devido a essa preocupação com a saúde e o bemestar físico, os atletas são mais críticos em relação ao seu corpo e peso, já que muitas vezes o êxito nas competições está relacionado à boa forma física. 
Existem muitas modalidades que exigem um corpo magro e belo, como: atletismo, ginástica artística, nado sincronizado, ginástica olímpica, hipismo e dança, principalmente balé (COSTA et al., 2007).

A associação entre transtornos alimentares, amenorreia e baixa densidade óssea é denominada de tríade da mulher atleta. Esses componentes estão vinculados à etiologia, patogênese e deficiência de ferro, irregularidades menstruais, desmineralização óssea (osteoporose) e danos musculoesqueléticos que podem interferir no desempenho do atleta, levando à morbidade e mortalidade. Outros sintomas clássicos da síndrome são: distúrbios do sono e de comportamento (irritabilidade), distúrbios de atenção, perda de massa muscular, aumento da frequência cardíaca e redução do rendimento durante o exercício. Embora a prevalência de AN e BN em atletas ainda não seja conhecida no Brasil, supõe-se que sua incidência aumentou de $15 \%$ para 62\% (OLIVEIRA et al., 2003; COSTA et al., 2007 ALVARENGA, 2008).

Para o tratamento desses transtornos alimentares é essencial uma equipe multidisciplinar e interdisciplinar. Essa equipe deve ser composta por: psiquiatras, nutricionistas, psicólogos, psicopedagogos, terapeuta familiar, clínico geral, enfermeiros (em caso de internação) e endocrinologistas (ALVARENGA; LARINO, 2002; SILVA; SOUZA, 2008; PINZON et al., 2004). O paciente necessita de cuidados e acompanhamento clínico constantes, devido à possibilidade de óbito que apresentam (DERMAN; SZABO, 2006).

No caso de TAem atletas, o treinador e patrocinador também precisam estar preparados para lidar com a patologia, assim como manter-se informados quanto a distúrbios de autoimageme TAs (COSTA et al., 2007).

Atualmente existem diversos instrumentos utilizados na mensuração e avaliação dos TAs, como o Eating Attitudes Test -EAT, que foi desenvolvido por Garner e Garfinkel (1979) apud Bighetti (2004), sendo um dos instrumentos utilizados para rastrear indivíduos com facilidade de desenvolver AN e BN. $O$ teste (Anexo 1) possui 26 questões que estão divididas em três escalas, sendo elas: a escala da dieta, que reflete a não aceitação de alimentos de alto valor calórico, e intensa preocupação com a forma física. A segunda escala reflete a bulimia, a preocupação com os alimentos que a pessoa cogita ingerir e os episódios de ingestão compulsiva dos mesmos, seguidos de vômitos ou métodos purgativos para evitar o ganho de peso. E a terceira escala baseiase no controle oral, que demonstra autocontrole em relação aos alimentos e reconhece forças sociais que estimulam a ingestão alimentar. $\mathrm{O}$ teste ainda possui seis opções de resposta, que variam de 0 a 3 pontos ( sempre equivale a 3 pontos, muitas vezes $=2$ pontos, às vezes $=1$ ponto, poucas vezes $=0$, quase nunca $=$ 0 e nunca $=0)$. A $25 \cdot{ }^{\text {a }}$ questão apresenta pontos em ordem inversa. $O$ ponto de corte estabelecido foi de 21 pontos (GARNER, GARFINKEL, 1979 apud BIGHETTI, 2004).

O teste Body Shape Questionnarie - BSQ é um questionário autoaplicativo com 34 questões (Anexo 2). Cada questão apresenta seis possibilidades de resposta: 1) Nunca, 2) Raramente, 3) Às vezes, 4) Frequentemente, 5) Muito frequente e 6) Sempre. É utilizado para avaliar nas últimas quatro semanas a preocupação com a forma física. Ele fornece uma avaliação dos distúrbios da imagem corporal e pode ser utilizado para avaliar a atuação desse distúrbio no desenvolvimento, na manutenção e na resposta ao tratamento de TAs. Adistorção da imagem corporal pode ser leve - 70 a 90 -, moderada - 90 a 110 - ou intensa - maior que 110 (FREITAS, 2002; KAKESHITA; ALMEIDA, 2006; NUNES, 2006).

A Escala de Silhuetas de Stunkard et al. (Anexo 3) consiste num conjunto de nove silhuetas de cada gênero, apresentada em cartões individuais (1 a 9). A figura 1 corresponde à figura mais magra; já a figura 9 , à mais pesada. O IMC médio varia de $17,5 \mathrm{~kg} / \mathrm{m}^{2}$ a $37,5 \mathrm{~kg} / \mathrm{m}^{2}$. Para obter o resultado do teste, o participante escolhe a figura que acredita ser condizente com a sua aparência corporal (eu) e a figura que considera ser ideal para sua composição corporal (ideal). A partir desse método se verifica o nível de insatisfação corporal dos indivíduos. Se o resultado for igual a zero (escolher a mesma figura como "eu" e "ideal"), é classificado como satisfeito. Se for diferente 
de zero, no caso de superestimar o peso (escolher uma figura maior como "eu" e uma menor como "ideal"), é classificado como insatisfeito. E a outra possibilidade de classificação seria a insatisfação pela magreza, em que o indivíduo escolhe uma figura menor como "eu" e uma maior como "ideal" (DAMASCENO, 2005; KAKESHITA; NUNES, 2006; ARAÚJO, 2007).

Segundo Gardner (1996) apud Kakeshita (2006), a imagem corporal é um componente que representa mentalmente a identidade pessoal, ou seja, é a figura mental que se tem das medidas, dos contornos, da forma do nosso corpo e dos sentimentos relacionados a essas características. O elemento subjetivo da imagem corporal relaciona-se à satisfação de uma pessoa com seu tamanho corporal ou partes específicas do corpo, que estão relacionados intensamente com os portadores de TAs, podendo estar presente também em praticantes de atividade física (PERES, SANTOS, 2006).

Diante das informações que foram expostas anteriormente, pretende-se com este estudo analisar possíveis casos de transtornos alimentares em atletas. Em seguida, investigar a autoavaliação da imagem corporal, o comportamento alimentar e o controle de peso, relacionando-os com a alimentação. Pretendese, ainda, verificar o estado nutricional das atletas por meio da avaliação antropométrica.

\section{Metodologia}

O grupo estabelecido para o estudo foi: 12 adolescentes de 14 a 17 anos, do sexo feminino, jogadoras de basquete.

Antes de iniciar a coleta dos dados, todos os testes foram explicados com relação ao seu preenchimento correto e as atletas foram distribuídas na sala, para que não se influenciassem com as respostas da colega ao lado. Em seguida os testes foram aplicados (EAT26, $B S Q$ e Silhuetas). Na sequência, as perguntas relacionadas à imagem corporal também foram aplicadas e, por fim, foi explicado como deveria ser o preenchimento do diário alimentar.

Os dados antropométricos foram obtidos através do peso, altura e dobras cutâneas (tríceps e subescapular) e utilizados para avaliar a composição corporal das atletas. Para isso se utilizou o indicador IMC por idade
- IMC/I, de acordo com a curva de percentil proposta pela National Council Health Statistics - NCHS (2000) para obtenção da classificação do estado nutricional das adolescentes.A partir das medidas obtidas foram calculadas: a porcentagem de gordura $(\% \mathrm{~GB}) \mathrm{e}$ o índice de massa corporal (IMC). Para a realização da atividade foram utilizadas três balanças portáteis da marca Plenna ${ }^{\circledR}$, com capacidade para $120 \mathrm{~kg}$ devidamente calibradas, e duas fitas métricas fixadas na parede para aferir a estatura.

A verificação das dobras cutâneas foi realizada com o auxílio de dois adipômetros da marca Lange®, devidamente calibrados e classificados segundo a tabela de percentis de dobra cutânea tricipital e subescapular para crianças e adolescentes da NCHS, 1980.

\section{Resultados e discussão}

Os resultados obtidos foram: no teste EAT-26 não houve prevalência de risco para o desenvolvimento de anorexia nervosa e bulimia nervosa, mesmos resultados observados na pesquisa do autor Oliveira et al. (2003), desenvolvida comatletas e não atletas. Em contrapartida, a pesquisa realizada pela autora Manochio (2005) em um grupo de risco (balé) observou que $36,4 \%$ (sete mulheres e um homem) dos dançarinos apresentaram pontuação elevada no EAT-26, ou seja, acima de 21 pontos, sendo este um fator positivo para o desenvolvimento de TAs.

\section{Teste de Silhuetas de Stunkard et al.}

No Teste de Silhuetas, de acordo com a Figura 1, $66,66 \%$ das participantes superestimaram o seu peso corporal (escolheram como "ideal" uma silhueta menor que a atual - "eu"), 16,67\% classificaram-se como satisfeitas e 16,67\% apresentaram insatisfação pela magreza. Comparando com o estudo realizado por Cachelin et al. (2002) apud Damasceno (2005), que também utilizou as Silhuetas de Stunkard et al., foi observado que as mulheres tendem a escolher as silhuetas menores que a atual. No estudo desenvolvido por Branco, Hilário e Cintra (2006), que correlacionou autopercepção da imagem corporal com o estado nutricional em mulheres e homens, foi constatado que 
$39 \%$ da população feminina tende a superestimar o seu peso, mesmo estando em estado de eutrofia. Fato este que também foi observado no presente estudo.

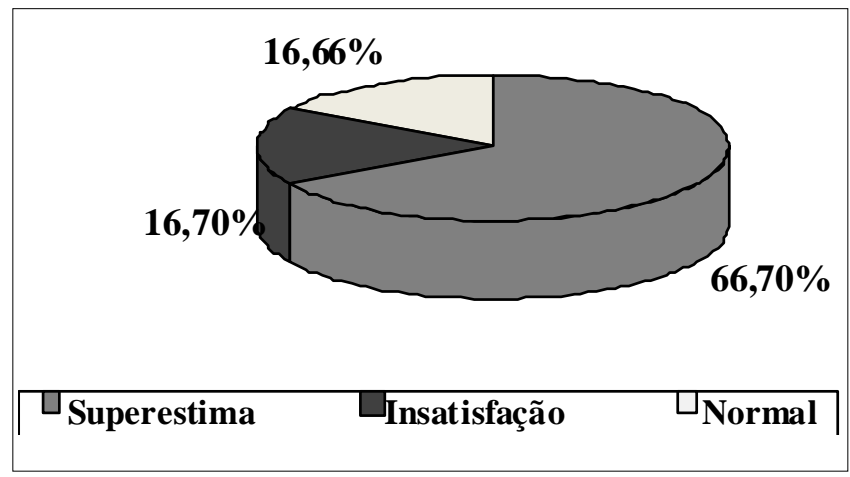

Figura 1 - Resultados obtidos (\%) no Teste de Silhuetas aplicados aos participantes do teste $(n=12)$.

Fonte: Dados de pesquisa.

\section{Teste $B S Q$}

O teste $B S Q$ demonstrou que $25 \%$ das participantes apresentaram uma leve distorção da imagem corporal; $16,7 \%$, uma distorção da imagem corporal moderada; e 58,3\% não apresentaram nenhuma distorção de imagem corporal (Figura 2). Ao analisarmos as porcentagens que indicaram algum tipo de distorção de imagem corporal (leve ou moderada), é possível observar que 41,7\% (5 jogadoras) apresentaram distorções, sendo este valor considerado alto, já que o grupo analisado é composto por 12 participantes. No estudo realizado por Oliveira et al. (2005) com atletas da EEFD-UFRJ observou-se que 33,3\% das atletas também apresentavam leve distorção da imagem corporal e 66,7\% tinham ausência dessa distorção. Em comparação, na pesquisa desenvolvida por Vieira et al. (2006) com atletas do judô do Estado do Paraná, foi observado que $50 \%$ das alunas da modalidade JAP's apresentaram leve distorção da imagem corporal; entre as atletas que pertenciam à modalidade JOJUP's, 44,8\% não tiveram distorção de imagem corporal, 24,14\% tiveram distorção leve, 20,6 tiveram distorção moderada e $10,3 \%$ apresentaram distorção grave. No recente estudo realizado com jogadoras de basquete, não foram observadas distorções graves nas mesmas.

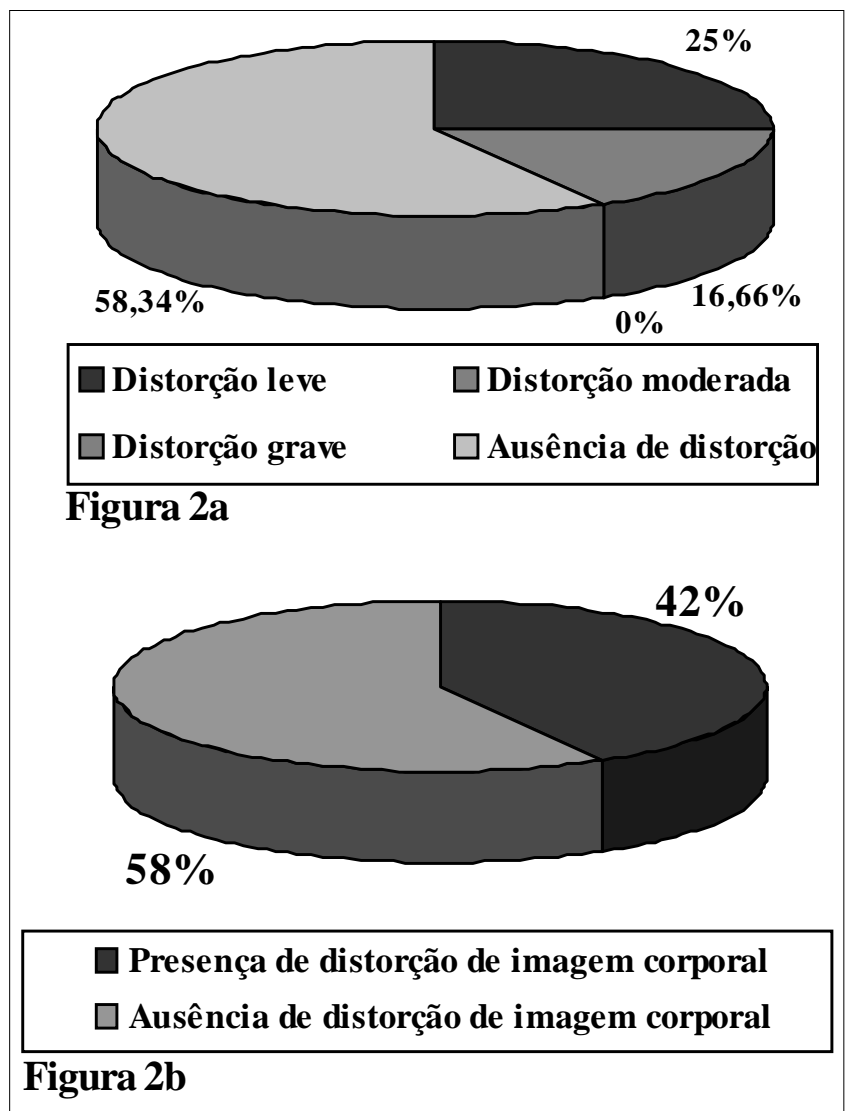

Figura 2 - Classificação do teste $B S Q$ (Figura 2a) e presença ou ausência de distorção da imagem corporal (Figura 2b).

Fonte: Dados de pesquisa.

\section{Avaliação antropométrica}

Os resultados relacionados à avaliação antropométrica (IMC) evidenciaram que $75 \%$ das jogadoras são eutróficas e $25 \%$ estão abaixo do peso (Figura 3). Na Porcentagem Gordura Corporal (\%GC), 66,7\% estão adequadas e 33,3\% apresentam gordura corporal abaixo do normal. $\mathrm{Na}$ pesquisa realizada com adolescentes praticantes de nado sincronizado, por Moroli et al. (2008), foi constatado que a média do IMC foi de $20,56 \mathrm{~kg} / \mathrm{m}^{2}$ (eutrofia) e o valor médio de porcentagem de gordura corporal foi de $20,1 \%$, sendo este adequado. Portanto, a maioria das adolescentes que praticam algum esporte apresentam composição corporal adequada. 


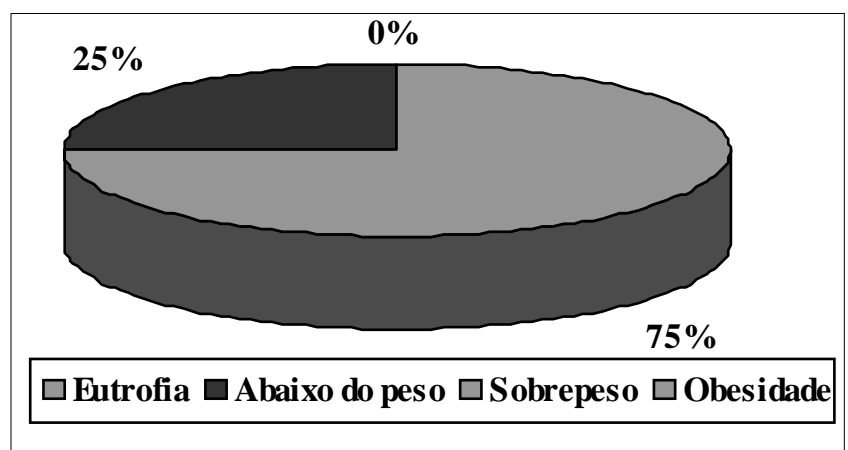

Figura 3-Resultados (\%) obtidos na avaliação antropométrica (IMC) aplicada aos participantes $(n=12)$.

Fonte: Dados de pesquisa.

No resultado da prega cutânea tricipital (PCT), $58,3 \%$ estão em estado de normalidade e $41,7 \%$, com pouca gordura. Na prega cutânea subescapular (PCSE), todas as participantes foram classificadas como eutróficas.

Nas questões relacionadas à vontade de mudar o seu corpo, $75 \%$ das participantes relataram ter este desejo, principalmente relacionando aos acúmulos de gorduras em determinadas partes do corpo, e $25 \%$ não mudariam nada.
Avaliando a alimentação, todas as participantes não possuem uma alimentação balanceada, de acordo com o diário alimentar, e não fazem as mínimas seis refeições diárias. Sendo assim, 91,6\% relataram ser necessário uma mudança nos hábitos alimentares, enquanto somente $8,34 \%$ reconhecem os hábitos errôneos e não demonstram desejo de mudança. Este comportamento também foi observado por Moroli et al. (2008) quando avaliaram o consumo alimentar das atletas do nado sincronizado. Foi constatado que $77 \%$ das atletas avaliadas pelos autores também não realizavam as mínimas seis refeições diárias.

Relacionando os resultados do Teste de Silhuetas de Stunkard et al. com o IMC das participantes, foi possível observar os dados expostos na Tabela 1: das 12 participantes, 2 estão abaixo do peso, segundo o IMC, embora as mesmas tenham escolhido as Silhuetas de 2 a 5, que são classificadas como eutróficas; 9 atletas que também escolheram as Silhuetas de 2 a 5 tiveram a mesma classificação comparadas ao IMC (eutrofia), e 1 participante, que escolheu as Silhuetas de 8 a 9, que indica obesidade, estava em estado de eutrofia pelo IMC.

Tabela 1 - Relação entre classificação da Silhueta e o IMC das participantes ( $n=12)$.

\begin{tabular}{ccccc}
\hline Estado & Silhueta 1 & Silhuetas 2-5 & Silhuetas 6-7 & Silhuetas 8-9 \\
nutricional & (Baixo Peso) & (Eutrofia) & (Sobrepeso) & (Obesidade) \\
\hline Baixo peso & - & 2 & - & - \\
Eutrofia & - & 9 & - & 1 \\
Sobrepeso & - & - & - & - \\
Obesidade & - & - & - & \\
\hline
\end{tabular}

Fonte: Dados de pesquisa. 


\section{Conclusão}

Apesar de este estudo não ter diagnosticado possíveis casos de TAs, foi possível concluir que a maioria das atletas apresenta distorção da sua imagem corporal, almejando um corpo perfeito (magro), muitas vezes incentivado pela mídia ou por relacionar, no caso das atletas, êxito nas competições a esta forma física.

Devido ao fato de muitos treinadores e atletas não terem conhecimento adequado sobre nutrição, o estado nutricional dos mesmos pode ser comprometido em razão da tentativa de manter um peso corpóreo abaixo do normal. É importante ressaltar que os treinadores precisam estar atentos para o surgimento de TAs entre os atletas, para que o desempenho no respectivo esporte não seja prejudicado ou até mesmo para que não se tenha a desistência do atleta pela modalidade.

Como o meio esportivo também é um preditor para a instalação de TAs, é indicado que os atletas sejam acompanhados por uma equipe multidisciplinar, que não priorize somente o desempenho esportivo, mas que proporcione qualidade de vida aos mesmos. Desse modo, é necessário que sejam desenvolvidos programas educativos direcionados a orientações sobre nutrição aos atletas.

Diante dos dados que foram expostos, torna-se apropriado o desenvolvimento de mais trabalhos científicos nesta área de pesquisa para elucidar uma maior prevalência de TAs em atletas, juntamente com a divulgação dos mesmos para conscientizar e informar a população e este grupo de risco.

\section{REFERÊNCIAS}

ALVARENGA, M.; LARINO, M. A. Terapia nutricional na anorexia e bulimia nervosas. Rev. Bras de Psiquiatria, São Paulo, v. 24, supl. 3, p. 39-43, dez. 2002.

ALVARENGA, M. Transtornos alimentares - um enfoque para a atividade física e o esporte. In: HIRSCHBRUCH, M.; CARVALHO, J. R. Nutrição esportiva: uma visão prática. Manole, 2008. cap.37, p. 295 - 306.
ALMEIDA, G. A. N. et al. Percepção de tamanho e forma corporal de mulheres: estudo exploratório.

Psicologia em estudo, Maringá, v. 10, n. 1, p. 27 35, jan./abr. 2005.

\section{AMERICAN PSYCHIATRIC ASSOCIATION} (APA). Diagnostic and statistical manual of mental disorder: text review - DSM-IV-TR. Washington, DC: 2000.

ARAÚJO, V. C.; GRAUP, S.; PEREIRA, E. F. Percepção da imagem corporal em relação ao estado nutricional em escolares. Fórum Internacional de esportes, 2007.

BIGHETTI, F. et al. Tradução e validação do Eating attitudes test em adolescentes do sexo feminino de Ribeirão Preto, São Paulo. J. bras. psiquiatr, v. 53, n. 6, p. 339 - 343, nov/dez. 2004.

BIGHETTI, F. et al. Transtornos alimentares: anorexia e bulimia nervosas. In: KALINOWSKI, C. Proenf: programas de atualização de enfermagem saúde do adulto. Artmed, 2006. cap. 2, p. 9-45.

BRANCO, L. M.; HILÁRIO, M. O. E.; CINTRA, I. P. Percepção e satisfação corporal em adolescentes e a relação com seu estado nutricional. Rev. Psiq. Clín., v. 33, n. 6, p. 292 - 296, maio. 2006.

BORGES, N. J. B. G. et al. Transtornos alimentares - quadro clínico. Méd. Ribeirão Preto, v. 39, n. 3, p. 340 - 348, jul/set. 2006.

CACHELIN et al., 2002 apud Damasceno. Tipo físico ideal e satisfação com a imagem corporal de praticantes de caminhada. Rev. Bras Méd Esporte, v. 11, n. 3, p.181-186, maio. 2005.

CORDÁS, T. A. et al. Transtornos alimentares: epidemiologia, etiologia e classificação. Rev. Nutrição Profissional. São Paulo, v. 3, n. 11, p. 12-20, 2007. 
COSTA, S. P. V. et al. Distúrbios da imagem corporal e transtornos alimentares em atletas e praticantes de atividade física. Revista Digital Buenos Aires, v. 12, n. 114, nov. 2007.

CRISP, A. H.; PALMER, R. L.; KALUCY, R. S. How commom is anorexia nervosa? A prevalence study. Br J Psychiatry, London, v. 128, p. 549554, 1976.

DAMASCENO, V. O. et al. Tipo físico ideal e satisfação com a imagem corporal de praticantes de caminhada. Rev. Bras Méd Esporte, v. 11, n. 3, p. 181 - 186, maio. 2005.

DERMAN, T.; SZABO, C. P. Why do individuals with anorexia die? Acase of sudden death. Int J Eat Disord, USA, v. 39, p. 260 - 262, abr. 2006.

FREITAS, S; GORENSTEIN, C; APPOLINÁRIO, J. C. Instrumentos para avaliação dos transtornos alimentares. Rev. bras. psiquiatr, v. 24, n. 3; p. 3438, ago. 2002.

GARDNER, 1996 Apud Kakeshita. Relação entre índice e massa corporal e a percepção da autoimagem em universitários. Rev. Saúde Pública, v. 40, n. 3, p. 497 - 504, fev. 2006.

GARNER; GARFINKEL, 1979 Apud Bighetti et al. Tradução e validação do Eating Attitudes Test em adolescentes do sexo feminino de Ribeirão Preto, São Paulo. J. bras. psiquiatr, v. 53, n. 6, p. 339 343, nov/dez. 2004.

KAKESHITA, I. S; ALMEIDA, S. S. Relação entre índice e massa corporal e a percepção da auto-imagem em universitários. Rev.Saúde Pública, v. 40, n. 3, p. 497 - 504, fev. 2006.

MANOCHIO, M. G. Ocorrência e fatores de risco de transtornos alimentares em alunos de uma escola de ballet clássico de Franca-SP,
2005. 60 f. Trabalho de Conclusão de Curso (Graduação em Nutrição) - Universidade de Franca, Franca.

MOROLI, A. S. et al. Características nutricionais de uma equipe de adolescentes atletas de nado sincronizado. Revista Digital, Buenos Aires, v. 12, n. 118, mar. 2008.

National Council Health Statistics (NCHS, 2000) adaptado de CDC (Center for Disease Control and Prevention) Growth Charts, 2000, mediante a colaboração do National Center for disease and Health Promotion.

National Council Health Statistics (NCHS, 1976 1980) para classificação de dobra cutânea tricipitale subescapular - Vital and Health Statistics Series 11, n²38, 1976 - 1980.

NEUMARK-SZAINER, D. et al. Does body satisfaction matter? Five-year longitudinal associations between body satisfaction and health behaviors in adolescent female and males. J. Adolesc Health, USA, v. 39, p. 244 - 251, ago. 2006.

NUNES, M. A. Transtornos alimentares e obesidade. 2. ed. Porto Alegre: Artmesd, 2006.

OLIVEIRA, F. P; BOSI, M. L. M; VIGÁRIO, P. S; VIEIRA. R. S. Comportamento alimentar e imagem corporal em atletas. Rev Bras Med Esporte, v. 9, n. 6, p. 348 - 356, nov/dez. 2003.

PERES, R. S.; SANTOS, M. A. Contribuições do desenho da figura humana para avaliação da imagem corporal na anorexia nervosa. Méd Ribeirão Preto, v. 39, n. 3, p. 361 - 370, jul/set. 2006.

PINHEIRO, A. P. et al. Genetics in eating disorders: extending the boundaries of research. Revista Brasileira de Psiquiatria, São Paulo, 2006. 
PINZON, V. et al. Peculiaridades do tratamento da anorexia e da bulimia nervosa na adolescência: a experiência do PROTAD. Rev. Psiq. Clin, v. 31, n. 4, p. 167 - 169, set. 2004.

SHILS, M. E. Tratado de nutrição moderna na saúde e na doença. 9. ed. São Paulo: Manole, v. 2. 2003.

SICCHIERI, J. M. F. et al. Manejo nutricional nos transtornos alimentares. Medicina (Ribeirão Preto), v. 39, n. 3, p. 371-374, ago, 2006.

SILVA, L. C.; SOUZA, L. Você tem fome de quê? Abordagem biopsicossocial de transtonos alimentares. Rev. Psicologia da UnC, v. 1, n. 2, p. 59-68, mar. 2008.

WOLINSKY, I.; HICKSON Jr, J. F. Nutrição no exercício e no esporte. 2. ed. São Paulo, Rocca: 1996.

SAPONIK, A.; BUENO, M. O.; LOBÃO, B. Tratamento - aspectos gerais. In: CLAUDINO, A. M.; ZANELLA, M. T. Guias de medicina ambulatorial e hospitalar: transtornos alimentares e obesidade. São Paulo: Manole, 2005.

VIEIRA, J. L. L. et al. Distúrbios de atitudes alimentares e sua relação com a distorção da autoimagem corporal em atletas de judô do estado do Paraná. Rev. de Educação Física/UEM Maringá, v. 17, n. 2, p. 177-184, nov. 2006.

Anexo 1 - Teste de atitudes alimentares (EAT).

S MF F AV R N

( ) ( ) ( ) ( ) ( ) ( ) 1. Costumo fazer dieta.

( ) ( ) ( ) ( ) ( ) ( ) 2. Como alimentos dietéticos.

( ) ( ) ( ) ( ) ( ) ( ) 3. Sinto-me mal após comer doces.

( ) ( ) ( ) ( ) ( ) ( ) 4. Gosto de experimentar novas comidas engordantes.

( ) ( ) ( ) ( ) ( ) ( ) 5. Evito alimentos que contenham açúcar.

( ) ( ) ( ) ( ) ( ) ( ) 6. Evito particularmente alimentos com alto teor de carboidratos (pão, batata, arroz, etc.).

( ) ( ) ( ) ( ) ( ) ( ) 7. Estou preocupado(a) com o desejo de ser mais magro(a).

( ) ( ) ( )( ) ( ) ( ) 8. Gosto de estar com o estômago vazio.

( ) ( ) ( ) ( ) ( ) ( ) 9. Quando faço exercício penso em queimar calorias.

( ) ( ) ( ) ( ) ( ) ( ) 10. Sinto-me extremamente culpado(a) depois de comer.

( ) ( ) ( ) ( ) ( ) ( ) 11. Fico apavorado(a) com o excesso de peso.

( ) ( ) ( ) ( ) ( ) ( ) 12. Preocupa-me a possibilidade de ter gordura no meu corpo.

( ) ( ) ( ) ( ) ( ) ( ) 13. Sei quantas calorias têm os alimentos que como.

( ) ( ) ( ) ( ) ( ) ( ) 14. Tenho vontade de vomitar após as refeições.

( ) ( ) ( ) ( ) ( ) ( ) 15. Vomito depois de comer.

( ) ( ) ( ) ( ) ( ) 16. Já passei por situações em que comi demais achando que não ia conseguir parar.

( ) ( ) ( ) ( ) ( ) ( ) 17. Passo muito tempo pensando em comida.

( ) ( ) ( ) ( ) ( ) ( ) 18. Acho-me uma pessoa preocupada com a comida.

( ) ( ) ( ) ( ) ( ) ( ) 19. Sinto que a comida controla a minha vida.

( ) ( ) ( ) ( ) ( ) ( ) 20. Corto minha comida em pedaços pequenos.

( ) ( ) ( )( ) ( ) ( ) 21. Levo mais tempo que os outros para comer.

( ) ( ) ( ) ( ) ( ) ( ) 22. As outras pessoas acham que sou magro(a) demais. 
( ) ( ) ( ) ( ) ( ) ( ) 23. Sinto que os outros prefeririam que eu comesse mais.

( ) ( ) ( ) ( ) ( ) ( ) 24. Sinto que os outros me pressionam a comer.

( ) ( ) ( ) ( ) ( ) ( ) 25. Evito comer quando estou com fome.

( ) ( ) ( ) ( ) ( ) ( ) ( ) Demonstro autocontrole em relação à comida.

Anexo 2 - Questionário sobre a imagem corporal (BSQ).

Gostaríamos de saber como você vem se sentindo em relação à sua aparência nas últimas quatro semanas. Por favor leia cada questão e faça um círculo apropriado. Use a legenda abaixo:
1. Nunca
4. Frequentemente
2. Raramente
5. Muito frequentemente
3. Às vezes
6. Sempre

Por favor, responda a todas as questões.

Nas últimas quatro semanas:

1. Sentir-se entediada faz você se preocupar com sua forma física?

$\begin{array}{llllll}1 & 2 & 3 & 4 & 5 & 6\end{array}$

2. Você tem estado tão preocupada com sua forma física a ponto de sentir que deveria fazer dieta?

$\begin{array}{llllll}1 & 2 & 3 & 4 & 5 & 6\end{array}$

3. Você acha que suas coxas, quadril ou nádegas são grande demais para o restante de seu corpo?

$\begin{array}{llllll}1 & 2 & 3 & 4 & 5 & 6\end{array}$

4. Você tem sentido medo de ficar gorda (ou mais gorda)? $\quad \begin{array}{llllll}1 & 2 & 3 & 4 & 5 & 6\end{array}$

5. Você se preocupa com o fato de seu corpo não ser suficientemente firme?

$\begin{array}{llllll}1 & 2 & 3 & 4 & 5 & 6\end{array}$

6. Sentir-se satisfeita (por exemplo após ingerir uma grande refeição) faz você sentir-se gorda?

$\begin{array}{llllll}1 & 2 & 3 & 4 & 5 & 6\end{array}$

7. Você já se sentiu tão mal a respeito do seu corpo que chegou a chorar?

$\begin{array}{llllll}1 & 2 & 3 & 4 & 5 & 6\end{array}$

8. Você já evitou correr pelo fato de que seu corpo poderia balançar?

$\begin{array}{llllll}1 & 2 & 3 & 4 & 5 & 6\end{array}$

9. Estar com mulheres magras faz você se sentir preocupada em relação ao seu físico?

$\begin{array}{llllll}1 & 2 & 3 & 4 & 5 & 6\end{array}$

10. Você já se preocupou com o fato de suas coxas poderem espalhar-se quando se senta? 
11. Você já se sentiu gorda, mesmo comendo uma quantidade menor de comida?

12. Você tem reparado no físico de outras mulheres e, ao se comparar, sente-se em desvantagem?

13. Pensar no seu físico interfere em sua capacidade de se concentrar em outras atividades (como por exemplo, enquanto assiste à televisão, lê ou participa de uma conversa)?

14. Estar nua, por exemplo, durante o banho, faz você se sentir gorda?

15. Você tem evitado usar roupas que a fazem notar as formas do seu corpo?

16. Você se imagina cortando fora porções de seu corpo?

$\begin{array}{llllll}1 & 2 & 3 & 4 & 5 & 6\end{array}$

17. Comer doce, bolos ou outros alimentos ricos em calorias faz você se sentir gorda?

18. Você deixou de participar de eventos sociais (como, por exemplo, festas) por sentir-se mal em relação ao seu físico?

19. Você se sente excessivamente grande e arredondada?

20. Você já teve vergonha do seu corpo?

$\begin{array}{llllll}1 & 2 & 3 & 4 & 5 & 6\end{array}$

21. A preocupação diante do seu físico leva-lhe a fazer dieta?

$\begin{array}{llllll}1 & 2 & 3 & 4 & 5 & 6\end{array}$

$\begin{array}{llllll}1 & 2 & 3 & 4 & 5 & 6\end{array}$

22. Você se sente mais contente em relação ao seu físico quando de estômago vazio (por exemplo pela manhã)?

23. Você acha que seu físico atual decorre de uma falta de autocontrole?

24. Você se preocupa que outras pessoas possam estar vendo dobras na sua cintura ou estômago?

25. Você acha injusto que as outras mulheres sejam mais magras que você? 
27. Quando acompanhada, você fica preocupada em estar ocupando muito espaço (por exemplo, sentado num sofá ou no banco de um ônibus)?

28. Você se preocupa com o fato de estarem surgindo dobrinhas em seu corpo?

29. Ver seu reflexo (por exemplo, num espelho ou na vitrine de uma loja) faz você sentir-se mal em relação ao seu físico?

30. Você belisca áreas de seu corpo para ver o quanto há de gordura?

31. Você evita situações nas quais as pessoas possam ver seu corpo (por exemplo, vestiários ou banhos de piscina)?

32. Você toma laxantes para se sentir magra?

33. Você fica particularmente consciente do seu físico quando em companhia de outras pessoas?

34. A preocupação com seu físico faz-lhe sentir que deveria fazer exercícios?

Anexo 3 - Escala de Silhuetas de Stunkard et al.

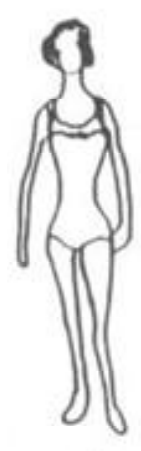

1
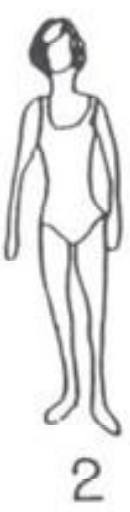

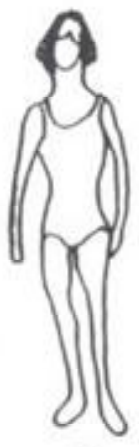

3
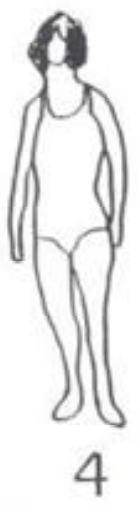

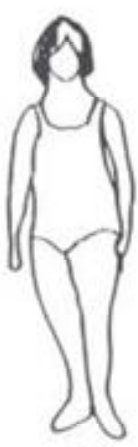

5

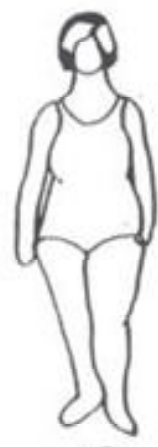

6

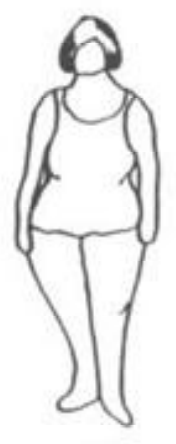

7
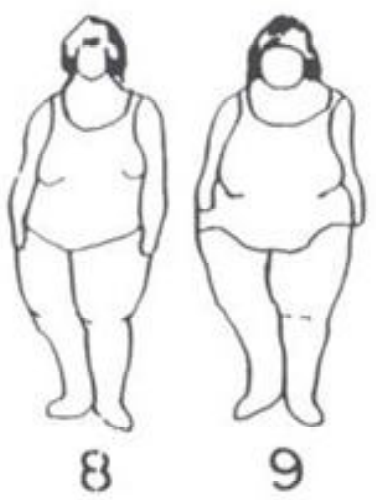

RECEBIDO EM 14/9/2010

ACEITO EM 10/12/2010 